\title{
Game Learning Analytics for Educators
}

\author{
Antonio Calvo Morata \\ Facultad de Informatica \\ Universidad Complutense de Madrid \\ Madrid, Spain \\ acmorata@ucm.es \\ Ivan Martinez-Ortiz \\ Facultad de Informatica \\ Universidad Complutense de Madrid \\ Madrid, Spain \\ imartinez@fdi.ucm.es
}

\author{
Cristina Alonso Fernandez \\ Facultad de Informatica \\ Universidad Complutense de Madrid \\ Madrid, Spain \\ calonsofernandez@ucm.es \\ Baltasar Fernandez-Manjon \\ Facultad de Informatica \\ Universidad Complutense de Madrid \\ Madrid, Spain \\ balta@fdi.ucm.es
}

\author{
Manuel Freire \\ Facultad de Informatica \\ Universidad Complutense de Madrid \\ Madrid, Spain \\ manuel.freire@fdi.ucm.es
}

\begin{abstract}
Serious games have proven several advantages when used in education improving students learning. However, games are still complex to deploy in the class for average teachers. Many teachers still do not see games as a powerful tool to improve their teaching work. To this end, it is essential to humanize the game technology making the use of games more transparent to teachers in a way that they get the benefits and avoid most of the game deployment complexity. We consider that Game Learning Analytics is one of the keys to help teachers in the application of serious games in the classrooms. Game Learning Analytics allows to capture data from students' interactions with games and derive information that simplify teachers' tasks. Doing it in a transparent way within the game environment (i.e. stealth assessment) can provide evidence-based data about the learners' knowledge at each point of time. Combining both game learning analytics in near real-time and offline, and stealth assessment for games, it could be possible to leverage their use in classroom settings at real-time making their use easier for teachers.
\end{abstract}

Keywords—serious games, learning analytics, game-based learning, educational data mining, stealth assessment

\section{INTRODUCTION}

The immersive and engaging nature of games has proven to be a promising and effective environment for learning [1]. These characteristics have increased the interest regarding serious games, that is, games which main purpose is other than entertainment [2]. Their main purpose may be learning, but also to raise awareness or change an attitude or behavior [3]. Many serious games have been developed in different areas (e.g. education, military), where they have proven to be an effective learning material [4], however few of them have gone through a formal validation process to prove that these games meet their intended goals (e.g. teach some topic, improve some skill) [5]. Moreover, most of the serious games were developed in controlled environments and are difficult to scale up and deploy in real scenarios by nonspecialist staff. A common scenario of application of serious games is in education, where games are used as an additional resource for educators who provide the game to students who play the game in class.

However, when it comes to actually apply serious games in educational settings, educators may face several issues (not only technological ones) that difficult their work:

- Specific technology or platform requirements: some games require a specific platform like Android or Windows and/or specific hardware components like special controllers. Not all schools are able to provide the specific technology requirements to apply the game successfully.

- Gameplay average duration: it is important to note whether the game is designed to be used in a short session of one or two hours or whether the opposite is intended to be played for several sessions throughout the course. If it is too long that may not fit in a single average class session and it will be necessary that the design of the game facilitates the dynamics to follow between different sessions.

- Adaptation for users with disabilities or special needs: for instance, if the game is geolocalized and the educator has students with motor disabilities, educators may not be able to apply the game.

- Number of devices: the number of devices where students play can be limited and the game may not be effective for players to play in a group.

Even if the game meets all the requirements for its application in the classroom, educators may not find its application that obvious. As educators, they may not be familiar with the technology used in the game and may not feel confident with the actual games' deployment. Training for teachers may also be required so they are provided with some tools to help them when applying the game and some guidelines on what educators and students need to do while the game is in play. Moreover, it can be difficult for educators to actually know what their students are doing while playing, whether they are actually learning or not, or how to adequately apply games in classes for they to be more effective.

To avoid these issues, it is key that developers and researchers keep in mind educators' needs and try to make games more "human" in terms of transparency and equity. Specifically, this means that games need to be both more transparent and reliable, so that educators do not need to be experts neither in games nor in technology for effectively using them. Regarding transparency, educators should be aware of what students are doing in the game at any moment and obtain information on whether they are learning or not. Reliability can be ensured if the game indeed meets their intended teaching goals, so educators can be sure that letting students play in class is an adequate learning activity.

To provide information that helps educators, interaction data can be collected from students' gameplays to provide a great insight into students' actions in the game. Learning Analytics data from games (i.e. Game Learning Analytics data) can be collected and analyzed to evaluate, validate and 
improve the games, but also to help educators avoid some of the previously mentioned issues. The application of Game Learning Analytics should not reduce educators' roles but change it as the learning activity also changes [6]. When collecting interaction data, equity also needs to be ensured. If developers or researchers are collecting data to improve the game design or deployment, also all the final stakeholders involved in the process, mainly educators and students, have to obtain a clear benefit of the use of this technology. Therefore, students should obtain a better and more authentic learning experience while teachers should keep control of their students obtaining real-time information about how they are playing the game and even data that can contribute to the final student evaluation. For students, equity can also be ensured if educational opportunities are provided according to students' level of need and ability [7].

Although the use of games in schools has proven to greatly benefit students, this does not mean that they are the only stakeholder to be taken into account. To promote the actual use of games in education, we consider that the full process should also consider educators as an essential part for those educational games that are going to be used in class, as they control and are the key stakeholder that applies games in their classes. Whether educators fully understand and know how to effectively apply games or not can greatly affect or even prevent the actual application of games with students. Therefore, we consider that educators should be key in the full lifecycle of those serious games designed to be used in class: from the initial game validation, applying games in classes obtaining information at real-time about their progress and results, and automatically evaluating students based on their in-game actions. Teachers' role needs to be pedagogically active at all stages: planning the session, during the gameplays and after the sessions [8].

Fig. 1 summarizes this full process where educators or teachers are placed in the center of the process and should be involved in all stages. Technology should simplify and not difficult their work: from games validation, applying games in class where data is being collected in an Analytics System, obtaining real-time information to know what students are doing while they play, and finally, being able to evaluate students based on their in-game actions.

In the following sections, we go through all the steps of the lifecycle of those serious games designed to be used in class focusing on educators' tasks and how game learning analytics data can simplify their use of this technology in classes. The rest of this paper is structured as follows. Section 2 describes some of the considerations and steps to formally validate serious games. Section 3 focuses on the application of games in actual classes, including what educators need to do before to prepare the activity, what information they can obtain while games are in play, and what they need to do after the gameplays are over. Section 4 proposes an additional use in which learning analytics data can be used to help educators evaluate students based on their in-game interactions. Finally, Section 5 summarizes the main conclusions of our work and points out some limitations.

\section{SERIOUS GAMES Formal VALIDATION}

To ensure games meet their intended goals, the first step is that they go through a formal validation stage. The most widely accepted and commonly used method to validate serious games is to conduct a pre-post experiment consisting of three phases: first, students complete a questionnaire before playing (pre-test), then students play the game from beginning to end, and finally, after finishing the gameplay, they complete a final questionnaire (post-test) [9]. Both pretest and post-test usually have the same (sub)set of questions. The goal is that this questionnaire assesses players' characteristics before and after playing about the topics covered in the game (the specific characteristic depends of

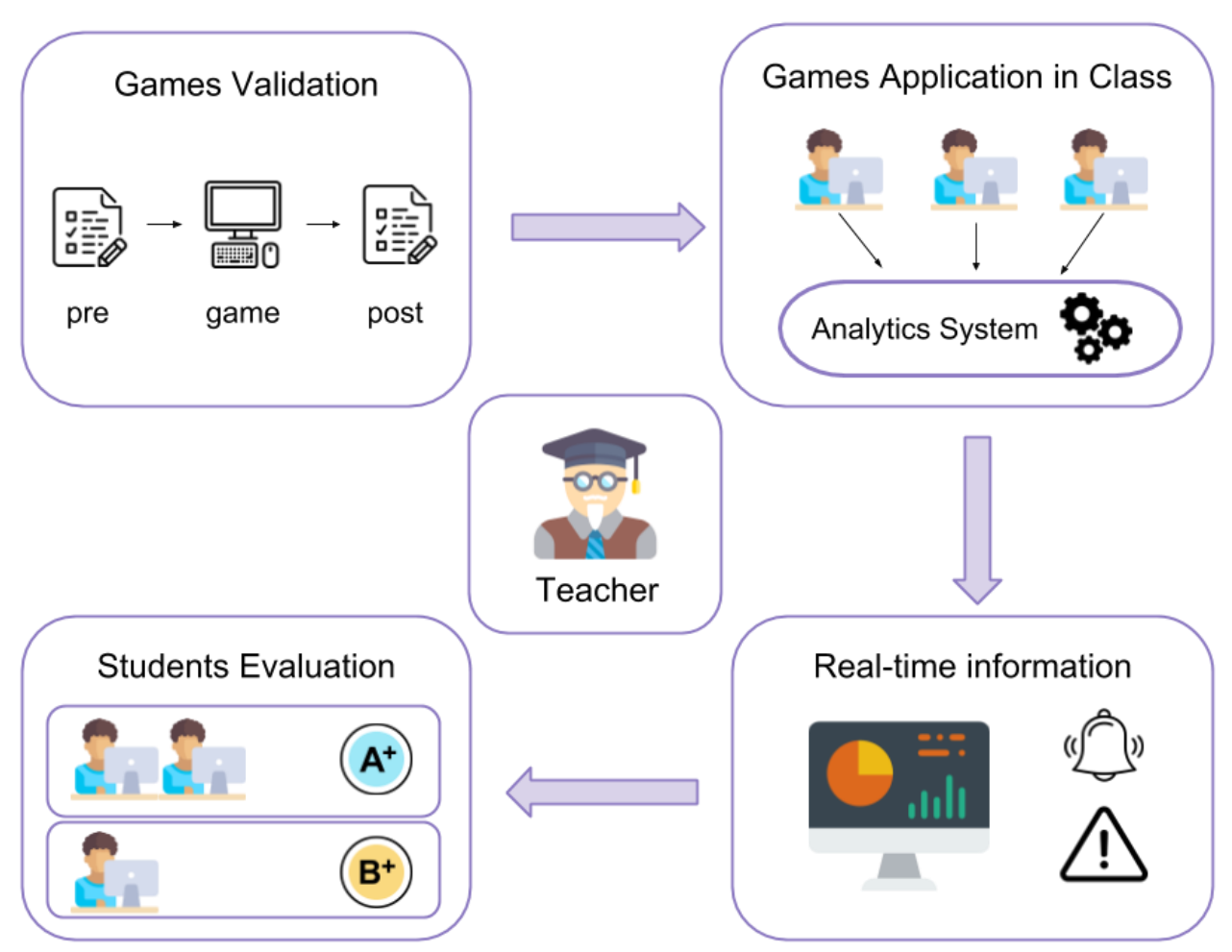

Fig. 1. Teachers' full process with serious games: From game validation, application in class, obtaining real-time information and evaluating students. 
the serious game purpose including, for instance, knowledge, attitude or awareness). Results of both tests are then compared to see if the increase in the specific player's characteristics is statistically significant. If that is the case, as between both measures the only intervention is the game, it can be concluded that the increase in that characteristic is due to the game effect, and therefore the game is formally validated. There are plenty of examples in literature that use this approach to validate serious games including, for instance: a game for children with autism to learn emotions [10], a game for patients to manage pain after surgery [11] or a game to raise awareness about bullying and cyberbullying [12].

In this validation stage, if we consider the case of a learning game designed to be used in class, the questionnaires provide a measure of how much students know about the topic before and after playing the game. In order to meet the equity and improve the validation process, researchers should provide the results to the teachers and how to assess the effectiveness of the game. The pre-test can provide educators a measure of how much students know about the topic before playing the game, or even it can be used as an assessment questionnaire to measure their knowledge of the topic. After playing, the post-test can show educators the effect of the game application and how much students know after playing (and, if the game is effective, also how much students have learned playing). The validation itself can easily be carried out during a class session where educators provide students the tests before and after playing the game and collect their results.

The validation process described, however, assumes that an accepted questionnaire that measures the specific characteristic (e.g. knowledge) covered in the game exists. But this assumption may easily not be satisfied, as few validated questionnaires already exist or have been constructed for serious games [13]. If there is no accepted questionnaire to validate the game, the complexity of the process escalates as, first of all, the validation questionnaire itself has to be developed and also validated. Once the game has been formally validated, it can actually be applied in larger classes as it is already proved that it is effective.

Learning analytics is also useful in this process, where collecting data from users can help to improve and validate the game design; for instance, to find bugs in the game, highlight features to improve and check if the game time and interactions are in line with the developer expectations.

\section{GAMES APPLICATION IN CLASS}

After their formal validation, the main scenario where games are applied is during a class session with at least one educator supervising the activity. Another possibility is that games are used for homework or as an additional optional activity to be carried out at home. However, this scenario would limit educators' involvement in the activity as they could only comment the activity with students in class a while before and after playing and they would not be able to interact with students while they are actually playing. This scenario also restricts the usefulness of the activity for educators at real-time as they cannot obtain information while students are actually learning (that is, while they are playing). Instead, if the game is played with internet connection and sending data to the analytics system, educators could receive information after gameplays have been completed. This information may include whether students have learned or not, if they have encountered issues playing or even assess students based on their in-game actions. As these previous scenarios avoid the possibility of educators' intervention, we focus on the common scenario of applying games in classes with at least one educator supervising the activity.

When applying games in classes, it is essential that educators fully understand the content and the mechanics of the game that they are applying. As a starting point, it would be ideal that educators have played the game before applying it with their students. Some educators may not consider it that useful as they are commonly not part of the intended target group of the game, however, actually playing the game can provide educators a great deal of information about what their students will face when they are the ones playing. Although we consider that playing the game is essential, only by playing educators may not have all the information about the purpose of each part of the game, the design decisions, etc. To complement the experience of playing the game as their students will do, a game manual for educators is extremely convenient so they can have all the information of the game to simplify its application in class. The manual for educators could include, among others: downloading (if needed) and installing instructions of the game; requirements for its application; goals the game aims to achieve; details about the game content (e.g. levels or days in-game, quests or tasks to complete, mini-games included, characters that appear, and even solutions or hints to solve game's challenges); purpose of each part of the game; additional information about the context of the topic the game is about (this can be used to raise a discussion with students after playing or to provide further information to complement and complete the content of the game); instructions for students; a list of frequently asked questions when applying the game, and so on. Some examples from literature where a manual has been provided to educators when applying games in class to support their tasks include [14] or [15].

Once educators are actually familiar with the game content and mechanics, a first step to make educators' task of applying games simpler has been achieved. Building up from this knowledge, it will now be much easier for educators to apply the game in their classes, helping students that need it and being aware of what students are actually facing in the game. But an additional step is required for educators to maintain control of what is happening in their classes when applying games. As students typically play individually, each student goes through different situations at each point of time, so it would be difficult for educators to be able to even know what each student is doing at a given moment. This can greatly undermine educators' trust in applying games in classes as they may feel that they do not longer control what students are doing. To avoid this perception, it is essential that educators obtain a complete-enough range of information while students are playing.

\section{A. Real-time information for educators}

A further step to simplify educators' task when applying games in schools is to ensure that they do not lose control of their students while they are playing. An easy way to give educators information about what students are doing in their gameplays is with some type of visual analytics that aggregates all the game learning analytics data coming from each student's gameplay. This visual information can be 
shaped as a dashboard, where multiple visualizations are combined to provide an overview of the class. It may also be helpful if this dashboard can be filtered by student so educators can also see the information about specific students or obtain more in-depth information about individuals, if needed. The dashboard should collect data from students' interactions with the game and show the information derived from that data at near real-time so educators can see the current situation of their students. The information shown may include: in which part of the game students are at each moment, chosen paths, progress, actions in the game, responses, scores, times, completion, etc. For instance, Fig. 2 shows an example dashboard for teachers including (from left to right, top to bottom): total number of active players, to verify that all students are playing; percentage of players who have reached each game ending, to know if all have reached the most desirable ending or not, which may depend on their in-game actions; number of players who have gone through each game-day, to know the general progress of the class in terms of game levels or days completed; number of scenes completed for each player, to know the specific progress of each student; and the value of one in-game metric (e.g. level of friendship with an in-game character) for each student, which may provide deeper insight into in-game actions taken.

An additional visual element that may help educators while games are in play is alert and warning messages [16]. These messages can be configured prior to the application of games (or be pre-configured by the game development team) so the conditions under which each specific alert or warning will be triggered are defined. When these conditions are met, the alert or warning message will be shown to the educator, together with the identifier of the student whose gameplay data has satisfied those conditions. With these defined messages, educators can be notified at near real-time when specific situations that may require their immediate attention occur. This system can be used so educators are able both to help students that encounter issues in their gameplays and

cannot move forward, and also to provide additional tasks to students that advance too fast and may finish the game earlier than expected. This method also improves equity as all students, regardless of their particular speed or ability to complete the game, can take advantage of the activity without wasting time getting stuck in the game or finishing it too early.

The previous process requires a fundamental point: the interactions carried out by students in the game need to be collected following some standard data format that can be used to define and populate the visualizations. In our proposal, we use the Experience API for Serious Games (xAPI-SG) profile [17] that standardizes the data collection for interactions performed in serious games. Following the definitions of this profile, it is recommended to provide a set of default teacher visualizations that covers the most common scenarios without any required additional information or configuration from teachers [18].

\section{B. Post-game activities}

When applying games in classes, it is also highly recommended there is some time left after the gameplays for educators. Hence, after students have completed their gameplays, educators can have a post-intervention activity prepared in advance. Each game may have a related activity associated with it, depending on the goal of the game. It is important that games provide the necessary tools so that educators can take advantage of them and relate them to the curricular content of the game:

- The post-game activity may be a simple discussion or debriefing about the common experience they have just gone through, so the game is the tool that triggers that discussion. This class discussion after playing games is key to promote reflection [19] in an open climate where students can share their experiences and feelings playing the game.

- Educators can use this time after the activity to help
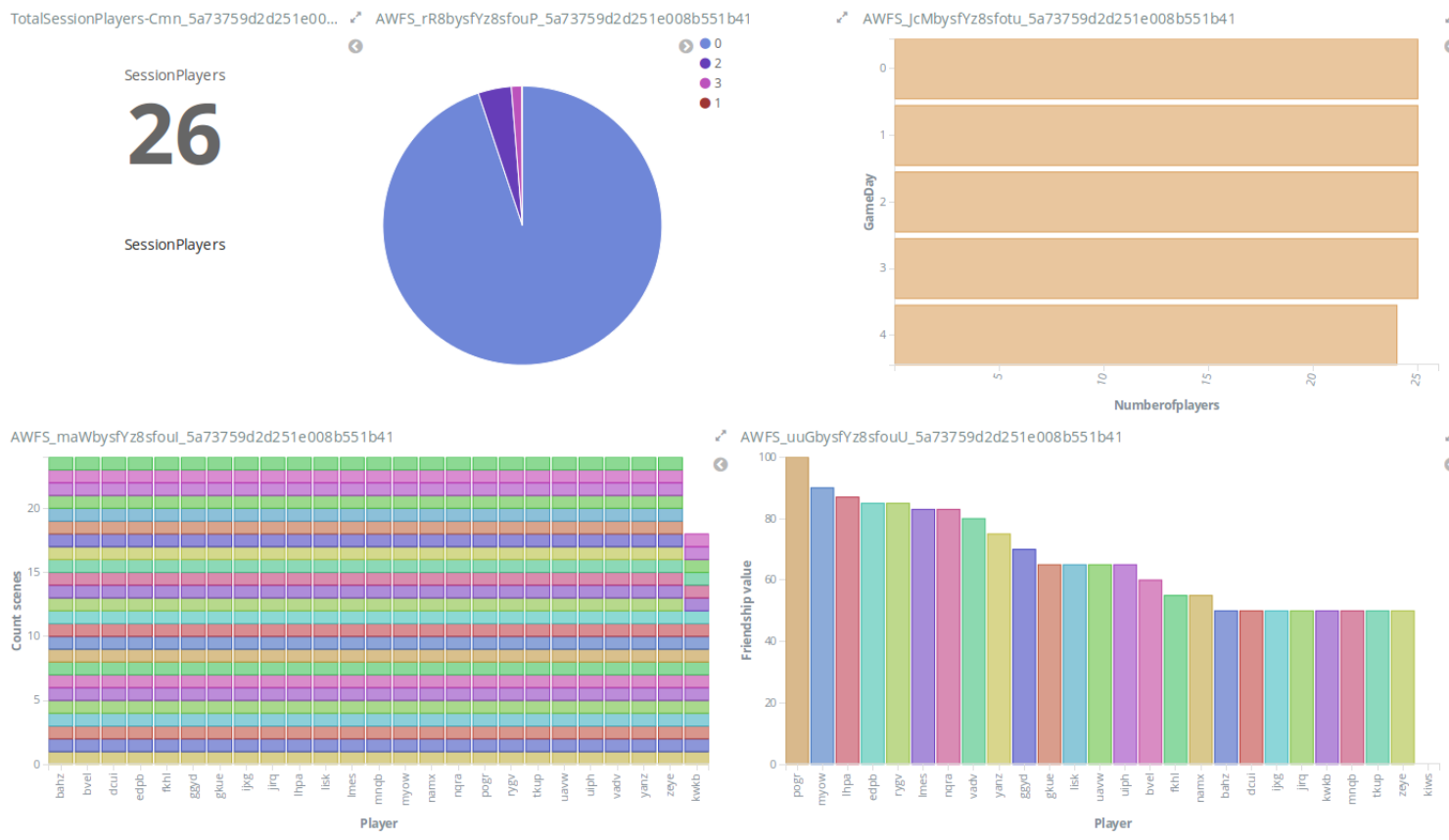

Fig. 2. Sample dashboard to show information for teachers while games are in play. 
students link the game content to that of the real world and include additional information that complements the gameplay. For instance, if the purpose of the game is increase knowledge, educators may provide additional information required in the curricula and not covered in the game or review the key take-home pieces of information. In the case of games to change attitude or increase awareness, the postgame discussion can be used to go through the topics covered in the game, extract conclusions and compare the situations depicted in the game to those students were familiar with.

- A final option is to provide players with some exercises where they can apply the content they have learned with the game. These exercises may be written (e.g. tests, or even homework) or oral (e.g. role playing), and may even be used for assessment purposes.

As mentioned before, some ideas for this post-game activity may also be included in the educators' manual. For instance, in [20] teachers reviewed the key concepts of the game after the activity to ground learning and connect the game content with the curricula.

Fig. 3 summarizes educators' activities before, during and after the application of game in classes. Before, reading the educators' guide and playing the game; during the application, following students' in-game actions and progress with visual information, alerts and warnings; after gameplays, guiding the discussion and helping students relate the content of the game with the curricula.

\section{STUdents Evaluation BAsEd ON IN-GAME INTERACTIONS}

A final step to simplify educators' tasks when applying games in education is that they are able to formally and automatically evaluate their students based on their actions playing the game. A commonly used method for students' evaluation follows the structure of that used when validating the game itself: players' knowledge is measured before and after playing with the pre-post questionnaires and the difference between the results in those tests shows how much students have learned playing. If the result obtained in the post-test is better than the one obtained in the pre-test, we can infer that students have learned something while playing the game. Although this is an effective method to evaluate learning, we consider that it is not that efficient. Players have to complete two times the same questionnaire (as the pre-test and post-test contains the same set of questions to be able to compare them) in addition to playing the game, that is what students would most probably be willing to do. This method also restricts the time left to play the game as well as the time left after students have finished playing for educators to either discuss the game content or to provide additional information about the topic if needed. Also, the questionnaires themselves need to be prepared in advance which takes time and effort, and also educators need to carry out the evaluation itself going through all the results in both pre-tests and post-tests to actually assess students.

For all these reasons, we consider that this pre-post method can be improved by taking advantage of the power of learning analytics data collected from in-game interactions. Following some of the aspects of the work done on stealth assessment [21], our proposal is to predict students' knowledge after playing (as usually measured by the posttest) based on the actions players carry out in the game. To do this, the first step is to create the prediction models that take as input the interaction data and output as result the knowledge predictions. The game validation step provides a great opportunity to create models that can accurately predict post-test results based on data from players' interactions in the game. In this step, we actually have the results from the questionnaires, so we can train the algorithms and evaluate their performance against the actual data (for instance, applying cross validation, all data collected can be used both to train and test the prediction models).

Once we have developed accurate enough models and selected the most promising one, we can use it as the assessment method for students who play the alreadyvalidated game. In this case, the model created will again take as input the information from students' interactions in the game and predict students' knowledge after playing the game based on these interactions. This method avoids the need to further carry out the post-test: students complete the pre-test (if needed), then play the game and, after their gameplays are finished, they will automatically be given a score that represents their knowledge after playing. The obtained score will be the result of the prediction model applied to the input data received from the student's gameplay. It may also be required that the pre-test is included as input for the prediction model, so we can measure how much knowledge is learned based on the previous knowledge students have (provided by the pre-test). Ideally, we would like to avoid the pre-test as well, so

\section{Before}

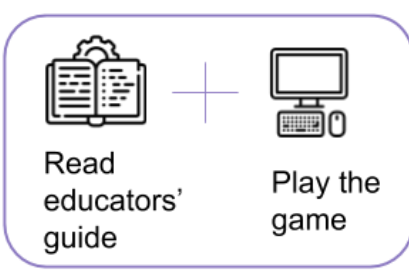

During

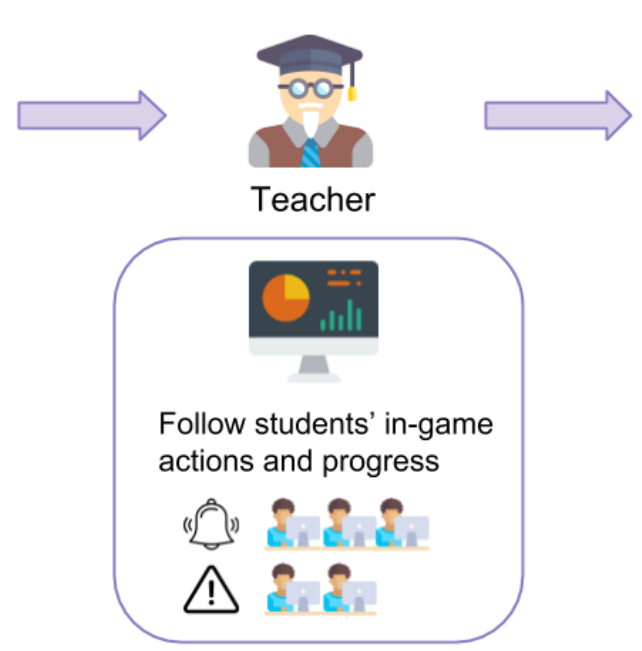

After

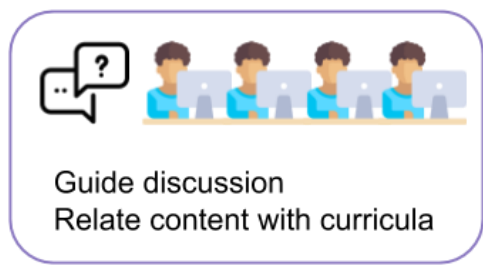

Fig. 3. Teachers' activities before, during and after using games in classes. 
prediction models could predict the post-test score only based on interaction data. In this case, the time to play the game and the time left for the educator could be even further extended as neither the pre-test nor the post-test will need to be carried out.

As in the case of obtaining real-time information while games are applied in classes, the described approach with prediction models is based on the key fact that all collected data from students' interactions must follow a standard data format. This standard data format is used as the format for the inputs received in the prediction models. Again, in our proposal, we use the accepted standard XAPI-SG profile to capture interactions from the serious games. As long as game interactions captured follow this standard, we consider that our approach could be more generalizable than the approach of stealth assessments, as once the prediction models are created at the validation stage, no further game-specific features are required to be able to evaluate students

\section{CONCLUSIONS}

The presence of games in education can still be greatly enhanced and extended. Educators are key to promote the application of games in actual educational settings. However, it cannot be expected that educators are experts in the use of technology, so games need to be both transparent and reliable, and provide the necessary tools to simplify educators' task. First of all, games need to be formally validated with an accepted method. A common accepted validation is with pre-post experiments, as long as a valid questionnaire exists that measures the characteristics the game aims to promote. After the game to be used has been formally validated, educators need to fully understand the content and the mechanics to be able to effectively use it in their classes. Playing the game before their students and going through the game manual can help educators to have enough information about the game to effectively apply it in classes. When students are immersed in their individual gameplays, visual information can help educators to keep control of their progress and actions. Alerts or warnings can also be used to make educators aware of specific situations that may require their intervention. Finally, analysis of learning analytics data from in-game interactions can provide educators a means of assessing students without an external measurement but based on what they actually do in the game. Prediction models developed at the game validation stage can automatically provide an evaluation of students' knowledge after playing the game based on their interaction data.

However, this full process has some limitations and requirements that need to be considered. The application of learning analytics with serious games is still fragile as they are still too many sources of possible errors. First of all, the deployment of games in schools may deal with technology failures as not all schools have the same materials. The data collection process can also fail if interaction data tracking is done to an analytics system that relies on the schools' internet connection. The analytics system also needs to be reliable and be ready to handle the data collected, both in size and format. All these technologies issues make that the application of games in schools still requires some technical support and may restrict the application by educators on their own. Another restriction that needs to be taken into account when collecting data, and that is even more important if data is from minors as it may frequently happen with serious games, is privacy and security. The data collected cannot contain any personal details about students, so the interaction data cannot be related to specific students. To ensure this, the analytics system should not retain the details about the students and all the data collected should be anonymized. To meet this requirement and ensure that information collected is still useful for educators, anonymous tokens can be given to students to use them as identifiers in the game and educators can keep the correspondence between tokens and students.

With all the steps described, we consider that educators' tasks when using games in education can be greatly simplified at all stages: from the initial games validation, actually applying games in classed in an effective and controlled way, and being able to assess students automatically based on their in-game actions. For all these steps, we consider that learning analytics data extracted from serious games is key to provide insight into students' actions when playing and simplify educators' application of games in class.

\section{ACKNOWLEDGMENT}

This work has been partially funded by the Regional Government of Madrid (eMadrid P2018/TCS4307), by the Ministry of Education (TIN2017-89238-R) and by the European Commission (RAGE H2020-ICT-2014-1-644187, BEACONING H2020-ICT-2015-687676, Erasmus+ IMPRESS 2017-1-NL01-KA203-035259).

\section{REFERENCES}

[1] T. M. Connolly, E. A. Boyle, E. MacArthur, T. Hainey, and J. M. Boyle, "A systematic literature review of empirical evidence on computer games and serious games," Comput. Educ., vol. 59, no. 2, pp. 661-686, Sep. 2012.

[2] Y. Chaudy, T. Connolly, and T. Hainey, "Learning Analytics in Serious Games : a Review of the Literature," Ecaet 2014, no. March 2016, 2014.

[3] W. Peng, M. Lee, and C. Heeter, "The Effects of a Serious Game on Role-Taking and Willingness to Help," J. Commun., vol. 60, no. 4, pp. 723-742, Dec. 2010.

[4] P. Backlund and M. Hendrix, "Educational games - Are they worth the Effort?: A literature survey of the effectiveness of serious games," in 2013 5th International Conference on Games and Virtual Worlds for Serious Applications, VS-GAMES 2013, 2013.

[5] M. Graafland, J. M. Schraagen, and M. P. Schijven, "Systematic review of serious games for medical education and surgical skills training," Br. J. Surg., vol. 99, no. 10, pp. 1322-1330, Oct. 2012.

[6] L. Y. (UoB) Dai Griffiths (UoB) Andrew Brasher (OU), Doug Clow (OU), Rebecca Ferguson, (OU), "Visions of the future, Horizon Report," 2016.

[7] M. Bienkowski, M. Feng, and B. Means, "Enhancing teaching and learning through educational data mining and learning analytics: An issue brief," Washington, DC SRI Int., pp. 1-57, 2012.

[8] M. Kangas, A. Koskinen, and L. Krokfors, "A qualitative literature review of educational games in the classroom: the teacher's pedagogical activities,” Teach. Teach., pp. 1-20, Jul. 2016.

[9] A. Calderón and M. Ruiz, "A systematic literature review on serious games evaluation: An application to software project management," 
Comput. Educ., vol. 87, pp. 396-422, Sep. 2015.

[10] S. Fridenson-Hayo et al., “"Emotiplay”: a serious game for learning about emotions in children with autism: results of a cross-cultural evaluation," Eur. Child Adolesc. Psychiatry, vol. 26, no. 8, pp. 979992, Aug. 2017.

[11] B. Ingadottir, K. Blondal, D. Thue, S. Zoega, I. Thylen, and T. Jaarsma, "Development, Usability, and Efficacy of a Serious Game to Help Patients Learn About Pain Management After Surgery: An Evaluation Study," JMIR Serious Games, 2017.

[12] A. Calvo-Morata, D. C. Rotaru, C. Alonso-Fernandez, M. Freire, I. Martinez-Ortiz, and B. Fernandez-Manjon, "Validation of a Cyberbullying Serious Game Using Game Analytics," IEEE Trans. Learn. Technol., pp. 1-1, 2018.

[13] I. Mayer et al., "The research and evaluation of serious games: Toward a comprehensive methodology," Br. J. Educ. Technol., vol. 45, no. 3, pp. 502-527, May 2014.

[14] S. Arnab et al., "The development approach of a pedagogically-driven serious game to support Relationship and Sex Education (RSE) within a classroom setting," Comput. Educ., vol. 69, pp. 15-30, Nov. 2013.

[15] A. Kampa, S. Haake, and P. Burelli, "Storytelling in Serious Games," in Lecture Notes in Computer Science (including subseries Lecture Notes in Artificial Intelligence and Lecture Notes in Bioinformatics), 2016, pp. 521-539.

[16] C. Alonso-Fernandez, A. Calvo, M. Freire, I. Martinez-Ortiz, and B. Fernandez-Manjon, "Systematizing game learning analytics for serious games," in 2017 IEEE Global Engineering Education Conference (EDUCON), 2017, pp. 1111-1118.

[17] Á. Serrano-Laguna, I. Martínez-Ortiz, J. Haag, D. Regan, A. Johnson, and B. Fernández-Manjón, "Applying standards to systematize learning analytics in serious games," Comput. Stand. Interfaces, vol. 50, pp. 116-123, 2017.

[18] A. Calvo-Morata, C. Alonso-Fernández, M. Freire, I. Martínez-Ortiz, and B. Fernández-Manjón, "Making Understandable Game Learning Analytics for Teachers," in 17th International Conference on Webbased Learning (ICWL 2018), Springer, 2018, pp. 112-121.

[19] M. Bakker, M. van den Heuvel-Panhuizen, and A. Robitzsch, "Effects of playing mathematics computer games on primary school students' multiplicative reasoning ability," Contemp. Educ. Psychol., vol. 40, pp. 55-71, Jan. 2015.

[20] C. Hébert and J. Jenson, "Digital Game-Based Pedagogy: Exploring Teaching Strategies for Classroom Teachers in the use of Video Games in K-12 Classrooms," in ECGBL 2017 11th European Conference on Game-Based Learning, 2017.

[21] V. Shute and M. Ventura, "Stealth Assessment," in The SAGE Encyclopedia of Educational Technology, 2455 Teller Road, Thousand Oaks, California 91320: SAGE Publications, Inc., 2013, p. 91. 